\title{
RNA Transcription Inhibition
}

National Cancer Institute

\section{Source}

National Cancer Institute. RNA Transcription Inhibition. NCI Thesaurus. Code C40692.

RNA T ranscription Inhibition involves interference with, or restraint of, the activities of the cellular process in which genetic information is transferred from DNA to messenger RNA by DNA-directed RNA polymerase. 